Article

\title{
Combined Effect of Tides and Wind on Water Exchange in a Semi-Enclosed Shallow Sea
}

\author{
Jiancheng Shang ${ }^{1,4}$, Jian Sun ${ }^{2} \mathbb{C}$, Lei Tao ${ }^{1}$, Yuanyi $\mathrm{Li}^{2,5,6, *}$, Zhenhua $\mathrm{Nie}^{3}$, Haiying Liu ${ }^{3}$, \\ Rui Chen ${ }^{1}$ and Dekui Yuan ${ }^{6}$ \\ 1 Tianjin Academy of Environmental Sciences, Tianjin 300191, China \\ 2 State Key Laboratory of Hydroscience and Engineering, Department of Hydraulic Engineering, \\ Tsinghua University, Beijing 100084, China \\ 3 Bureau of Ecology and Environment of Binhai New Area of Tianjin, Tianjin 300457, China \\ 4 Tianjin Huanke Environment Consulting Co., Ltd., Tianjin 300457, China \\ 5 Chinese Research Academy of Environmental Sciences, Beijing 100021, China \\ 6 Department of Mechanics, School of Mechanical Engineering, Tianjin University, Tianjin 300354, China \\ * Correspondence: liyuanyi@tju.edu.cn
}

Received: 23 July 2019; Accepted: 21 August 2019; Published: 23 August 2019

\begin{abstract}
The Bohai Sea is a semi-enclosed shallow sea in China, where the tides and wind are the dominant factors contributing to the water exchange with the Yellow Sea. However, existing studies on this water exchange primarily consider only the effect of tidal action, neglecting the contribution of wind. In this study, numerical models were used to simulate the hydrodynamic processes and tracer transport, with the consideration of both tides and wind. Based on the models, the two time scales, age and half-life, are applied to study the water exchange in the Bohai Sea quantitatively. The results show that the age and half-life decrease significantly when wind is included in the simulation, revealing that wind is an important contributor to the water exchange in such a semi-enclosed shallow sea. Under the combined forcing of tides and wind, the water transport in the Bohai Sea becomes clockwise, in contrast with the counterclockwise transport driven by the tides only. The seasonal-varying wind leads to a fluctuation of water exchange in an annual cycle, with the stronger water exchange in the northern (Liaodong Bay) and the western (Bohai Bay) regions of the Bohai Sea in winter and in the southern part (Laizhou Bay) in summer.
\end{abstract}

Keywords: wind; tide; water exchange; tracer; age; half-life

\section{Introduction}

Regions around semi-enclosed seas are generally less hazardous for shipping traffic and are home to a large portion of the world's population. However, these large populations generate high levels of pollution, which is discharged into the ocean and can have significant effects on the natural environment. As a result, semi-enclosed seas around the world often face environmental problems [1-10].

The Bohai Sea is a semi-enclosed shallow sea off the coast of northern China. The several decade long economic boom in this region has coincided with a decline in water quality [11-13]. Due to its semi-enclosed nature, water exchange with the Yellow Sea and the larger Pacific Ocean is weak leading to a buildup of land-based pollution [11]. Although the reduction of the pollution load is one of the important measurements of the water quality improvement, knowing the water exchange rate, which is an intrinsic condition determining the physical self-purification ability and water quality, is necessary to protect the Bohai Sea from water quality degradation.

It has been found that the tides and wind are the two predominant driving forces controlling the water exchange in the Bohai Sea [14]. Tides are an enduring driving force of water exchange in such a 
semi-enclosed sea and the tide-induced water exchange can be represented by either the Lagrangian or Eulerian residual flow circulations. Both Lagrangian and Eulerian residual currents have been used to represent the circulations, although the former one is considered as a more representative approach than the latter, especially in the shallow water zones where the nonlinearity is significant. With regard to the whole Bohai Sea or the bay scale, their circulation patterns from the two kinds of residual currents are similar to each other. Generally, the long-term transport driven by the tides is considered to be counterclockwise [15-17]. The water enters the Bohai Sea through the northern Bohai Strait and flows out through the southern part of the strait [18]. In addition, there also are some small-scale local circulations in the Bohai Sea, indicating the complexity of water transport driven by the tides. Based on the field observations, Zhao et al. [18] and Xu et al. [19] found that there is a tidally-driven clockwise circulation in the north part of the Liaodong Bay. Based on the combination of numerical modeling and geochemical analysis, Li et al. [6] suggested that as many as three tide-driven circulations may exist in the Bohai Bay. Water flow in the Bohai Sea was simulated by Hainbucher et al. [20] and several small clockwise and counterclockwise circulations were found in the central basin.

The wind-driven currents in the Bohai Sea have the same order of magnitude of the residual flows $\left(10^{-1} \mathrm{~m} / \mathrm{s}\right)$ [16]. Consequently, wind is also an important factor determining water exchange in the Bohai Sea. However, there are few studies on the contribution of wind to the water exchange in the Bohai Sea, and there is no consensus on the quantity of the contribution and the pattern of the wind-driven transport. It has been considered that the water transport driven by wind is also counterclockwise $[15,16]$, which is similar to the tide-induced water circulation. In contrast, based on a field observation, $\mathrm{Xu}$ et al. [21] suggested that the water circulation in the central basin of the Bohai Sea is clockwise. This may be related to the spatial and temporal wind variations. Due to the frequent variation of wind speed and direction over short time scales, determining the patterns of wind-driven water transport is complex. Under these conditions, the evaluation on the short-term water transport may not achieve consistent residual flows and therefore cannot give a clear answer to the physical self-purification ability of the Bohai Sea. Consequently, it is necessary to use auxiliary variables to represent the water exchange comprehensively.

The timescales of water exchange are indicators of the physical self-purification ability in the coastal ocean. Several timescales representing the different properties of water exchange have been proposed, such as half-life, residence time, flushing time, exposure time, and age. Among the timescales, the concept of the half-life is the simplest and it is defined as the time that it takes for half of the water in a basin to be exchanged with another region. As a property of a waterbody, the half-life is often used to qualify the water exchange rate in semi-enclosed waterbodies [22,23]. Age is another timescale used to qualify the water exchange and it is defined as the time elapsed since a water parcel entered the domain of interest, which is a concept of a Lagrangian nature. A general theory of water age was established by Delhez et al. [24] and Deleersnijder et al. [25] as well as an Eulerian method to solve it. Applying this theory, age has become a widely used timescale to study the water transport and environment issues [23,25-31].

In this study, numerical models of age and tracer are applied to the study on the water exchange in the Bohai Sea subjected to both the tides and wind. Based on the results of the models, the effect of wind on water exchange with the Yellow Sea is quantified by analyzing the transport patterns driven by both the tides and wind. In Section 2, we introduce the study area, as well as the numerical tools including the hydrodynamic model, the tracer transport model, and the Eulerian age model with the wind forcing and model setup. In Section 3, the results of the age model and tracer transport model are shown, and the effects of wind on the water exchange in the Bohai Sea are discussed based on the concepts of age and half-life. Section 4 summarizes the study and gives the conclusions drawn from the results. 


\section{Materials and Methods}

\subsection{Study Area}

The Bohai Sea is a semi-enclosed shallow sea located between northern and northeastern China and adjacent to Beijing, the capital city of China, and Tianjin, an important port. There are three bays including Liaodong Bay, Bohai Bay and Laizhou Bay (Figure 1) in the Bohai Sea. The three bays are connected to the central basin. The Bohai Strait is located on the east side of the Bohai Sea and connects the central basin with the Yellow Sea.

The water column in the Bohai Sea is shallow, with an average of $18 \mathrm{~m}$. The deepest area is approximately $86 \mathrm{~m}$ at the northern end of the Bohai Strait. The semi-diurnal tidal component $\mathrm{M}_{2}$ is the dominant tidal constituent with an average amplitude of $2 \mathrm{~m}$. There are three major rivers connected to the Bohai Sea, including the Yellow River, the Liao River and the Hai River. However, the discharges into the Bohai Sea are limited [32]. Yellow River is the largest river discharging into the Bohai Sea. The maximum flux of the Yellow River occurs in the summer, with the value being $\sim 5000 \mathrm{~m}^{3} / \mathrm{s}$ in a short period. The average flux of the Yellow River is $\sim 600 \mathrm{~m}^{3} / \mathrm{s}$ during the other seasons with zero-fluxes occurring occasionally. As to the other rivers, there is almost no flux discharged into the Bohai Sea during most of the year, due to not only the small runoffs, but also the floodgate control. Therefore, the salinity stratification is relatively weak with little effect on the movement of water [14,20].

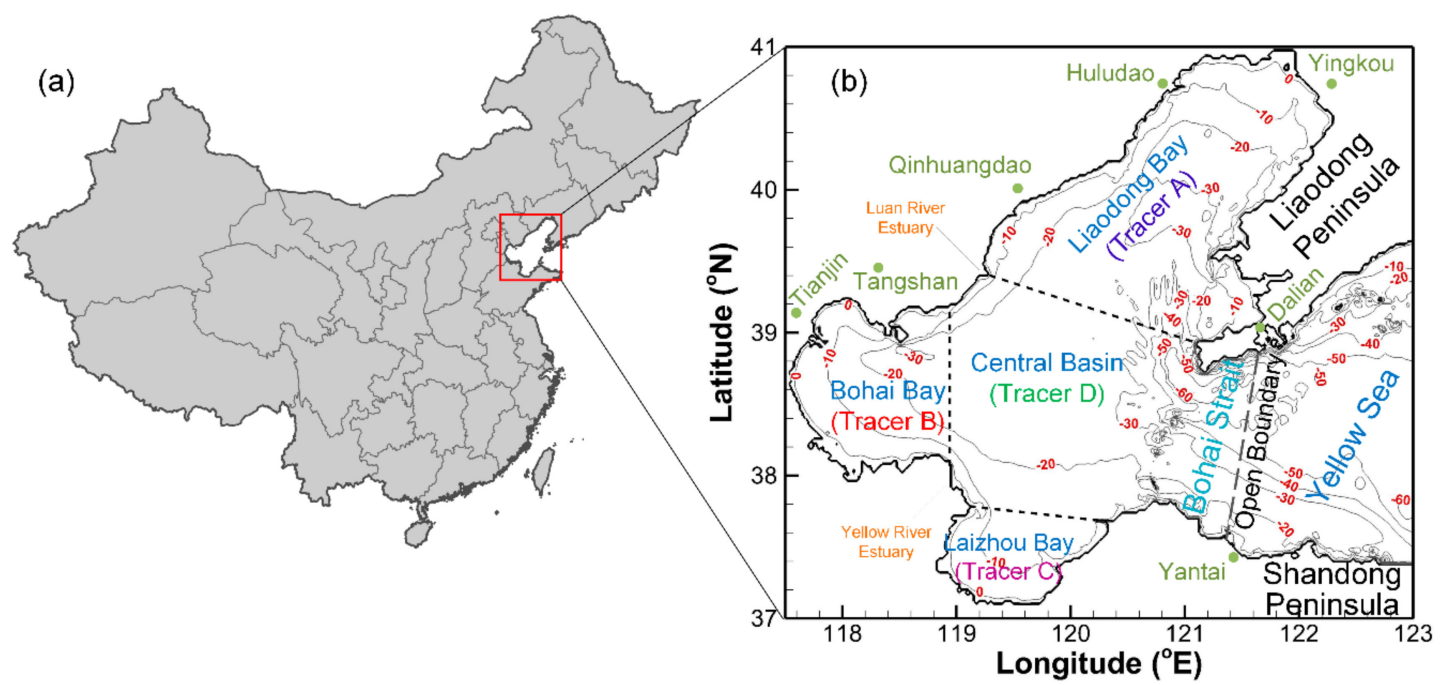

Figure 1. The location (a) and bathymetry (b) of the Bohai Sea and its subregions.

\subsection{Hydrodynamic Model}

Due to the shallow water depth, the water in the Bohai Sea is fully mixed in the vertical direction. Therefore, a two-dimensional hydrodynamic model $[33,34]$ developed by our team is applied in this study to simulate the circulation. The governing equations of the hydrodynamic model are the Reynolds-Averaged Navier-Stokes equations with vertical integration from the bottom to the free surface of the ocean, and they are as follows:

Mass conservation equation:

$$
\frac{\partial \zeta}{\partial t}+\frac{\partial p}{\partial x}+\frac{\partial q}{\partial y}=S
$$

and momentum conservation equations:

$$
\frac{\partial p}{\partial t}+\frac{\partial(\beta p U)}{\partial x}+\frac{\partial(\beta p V)}{\partial y}=f q-g H \frac{\partial \zeta}{\partial x}+\frac{\tau_{w x}}{\rho}-\frac{\tau_{b x}}{\rho}+\varepsilon\left(\frac{\partial^{2} p}{\partial x^{2}}+\frac{\partial^{2} p}{\partial y^{2}}\right)
$$




$$
\frac{\partial q}{\partial t}+\frac{\partial(\beta q U)}{\partial x}+\frac{\partial(\beta q V)}{\partial y}=-f p-g H \frac{\partial \zeta}{\partial y}+\frac{\tau_{w y}}{\rho}-\frac{\tau_{b y}}{\rho}+\varepsilon\left(\frac{\partial^{2} q}{\partial x^{2}}+\frac{\partial^{2} q}{\partial y^{2}}\right)
$$

where $H$ is the local water depth; $\zeta$ is the local water level; $S$ is the source or sink term of the water mass; $\rho$ is the density of the seawater; $g$ is the gravity acceleration; $p$ and $q$ are the transports $\left(\mathrm{m}^{2} / \mathrm{s}\right)$ in the $x$ and $y$ direction; $U$ and $V$ are the velocity components in the $x$ and $y$ directions, respectively; $\beta$ is the momentum correction coefficient caused by the non-uniform velocity profile in depth (due to the shallow water depth and absence of the salinity stratification, $\beta$ is assigned as 1 ); $f$ is the coefficient of the Coriolis Force ( $f=2 \omega \sin \alpha$, where $\omega$ is the angular frequency of self-rotation of the earth and $\alpha$ is the local latitude); $\tau_{w}$ and $\tau_{b}$ are the wind stress and the seabed stress, respectively; and $\varepsilon$ is the comprehensive diffusion coefficient including the molecular viscous diffusion and eddy viscous diffusion in the horizontal direction.

In this model, the governing equations are numerically solved using the finite difference method and the alternating direction implicit scheme [35]. The computational domain is discretized by staggered rectangular cells (C-grid), with the local water levels and water depths being specified at the centers of the cells and the velocities and fluxes defined at the middle points of the cell edges.

\subsection{Tracer Transport Model and Eulerian Age Model}

The Eulerian theory of age proposed by Delhez et al. [24] and Deleersnijder et al. [25] was based on the age concentration and mass concentration of a passive tracer. In the theory, the mean age was calculated as:

$$
a(t, \mathbf{x})=\frac{\alpha(t, \mathbf{x})}{C(t, \mathbf{x})}
$$

where $C(t, \mathbf{x})$ is the concentration of the tracer and $\alpha(t, \mathbf{x})$ is the age concentration that is defined as:

$$
\alpha(t, \mathbf{x})=\int_{0}^{\infty} \tau c(t, \mathbf{x}, \tau) \mathrm{d} \tau
$$

where $c(t, \mathbf{x}, \tau)$ is the age concentration distribution representing the mass concentration with the age $\tau$ at the spatial coordinate $\mathbf{x}$ at time $t$. The relation between $C(t, \mathbf{x})$ and $c(t, \mathbf{x}, \tau)$ is

$$
C(t, \mathbf{x})=\int_{0}^{\infty} c(t, \mathbf{x}, \tau) \mathrm{d} \tau
$$

According to the theory of Delhez et al. [24] and Deleersnijder et al. [25], both $C(t, \mathbf{x})$ and $\alpha(t, \mathbf{x})$ are controlled by advection-diffusion equations which can be expressed as:

$$
\begin{gathered}
\frac{\partial(H C)}{\partial t}+\frac{\partial(p C)}{\partial x}+\frac{\partial(q C)}{\partial y}=\frac{\partial}{\partial x}\left(H D_{x x} \frac{\partial C}{\partial x}+H D_{x y} \frac{\partial C}{\partial y}\right)+\frac{\partial}{\partial y}\left(H D_{y x} \frac{\partial C}{\partial x}+H D_{y y} \frac{\partial C}{\partial y}\right) \\
\frac{\partial(H \alpha)}{\partial t}+\frac{\partial(p \alpha)}{\partial x}+\frac{\partial(q \alpha)}{\partial y}=\frac{\partial}{\partial x}\left(H D_{x x} \frac{\partial \alpha}{\partial x}+H D_{x y} \frac{\partial \alpha}{\partial y}\right)+\frac{\partial}{\partial y}\left(H D_{y x} \frac{\partial \alpha}{\partial x}+H D_{y y} \frac{\partial \alpha}{\partial y}\right)+H C
\end{gathered}
$$

where $D_{x x} D_{x y} D_{y x}$ and $D_{y y}$ are the diffusion-dispersion coefficients, including the diffusion caused by turbulence and the vertical velocity distribution [36,37]. In this study, the diagonal terms $D_{x x}$ and $D_{y y}$ are calculated using formulae $D_{x x}=\lambda H U$ and $D_{y y}=\lambda H V$ with the dimensionless parameter $\lambda$ is set as 3.3 according to the analysis by Nie and Tao [37], and the other terms $\left(D_{x y}\right.$ and $\left.D_{y x}\right)$ are set as $0[36,38]$. According to this theory, a tracer model and an age model are established by our team as well [39].

\subsection{Wind Forcing}

The wind data used to drive the hydrodynamic model was obtained from the NCEP Climate Forecast System Reanalysis (NCEP CFSR) six-hourly product [40]. The dataset covers the period from January 1979 to March 2011 with a spatial resolution of $0.312^{\circ} \times 0.312^{\circ}$. In this study, the components 
of the wind speed at the computational grid nodes of the hydrodynamic model were calculated using the linear interpolation. Then the wind stresses $\left(\tau_{w x}\right.$ and $\left.\tau_{w y}\right)$ in $x$ and $y$ directions were calculated using the formula:

$$
\begin{aligned}
& \tau_{w x}=C_{d} \rho_{a i r} U_{10} \sqrt{U_{10}^{2}+V_{10}^{2}} \\
& \tau_{w y}=C_{d} \rho_{a i r} V_{10} \sqrt{U_{10}^{2}+V_{10}^{2}}
\end{aligned}
$$

here $\rho_{\text {air }}$ is density of air, $U_{10}$ and $V_{10}$ are the components of wind velocity in the $x$ and $y$ directions. $C_{d}$ is the drag coefficient of wind and can be expressed as [41]:

$$
C_{d}=\left\{\begin{array}{l}
\left(0.8699+0.0599 \sqrt{U_{10}^{2}+V_{10}^{2}}\right) \times 10^{-3}, \sqrt{U_{10}^{2}+V_{10}^{2}} \leq 10 \mathrm{~m} / \mathrm{s} \\
\left(0.8719+0.0704 \sqrt{U_{10}^{2}+V_{10}^{2}}\right) \times 10^{-3}, \sqrt{U_{10}^{2}+V_{10}^{2}}>10 \mathrm{~m} / \mathrm{s}
\end{array}\right.
$$

\subsection{Model Setup}

The study area covers the Bohai Sea including Liaodong Bay, Bohai Bay, Laizhou Bay and the central basin. It was discretized using rectangular cells with a resolution of $0.025^{\circ} \times 0.020^{\circ}$ in longitudinal and latitudinal directions (approximately $2196 \mathrm{~m}$ in longitude and $2220 \mathrm{~m}$ in latitude), respectively. The bathymetry in the Bohai Sea was obtained and digitized from the marine chart (Published by the Navigation Guarantee Department of the Chinese Navy Headquarters, NGDCNH) [42] and was assigned at the center of each cell. The boundary along the shoreline are set as a wall-water and tracers cannot penetrate the boundary. The velocity on the boundary is nonzero and it is tangential to the boundary. Considering the flood and ebb of tides, the water surface varies and the shoreline moves back and forth. To maintain the water and momentum balance, a wetting and drying algorithm [43] is used to the wall boundary to determine the actual location of the shoreline. The open boundary of the model is located along the Bohai Strait with the two ends at Dalian and Yantai (see Figure 1). The tidal harmonic constants of eight tidal components (i.e., $\mathrm{M}_{2}, \mathrm{~S}_{2}, \mathrm{~N}_{2}, \mathrm{~K}_{2}, \mathrm{~K}_{1}, \mathrm{O}_{1}, \mathrm{P}_{1}$ and $\mathrm{Q}_{1}$ ) obtained from Admiralty [44] are used to calculated the time series of the water levels at Dalian and Yantai, and the water levels at every point along the open boundary are calculated by linear interpolation based on the water level time series at those locations. The Bohai Sea is located in the temperate zone and the weather events with a large gradient of air pressure such as the typhoon are seldom in this region. Previous studies have indicated that the effect of air pressure gradient is negligible comparing to that of wind stress even when the cold air invasion occur [45-47]. Therefore, the term of the air pressure gradient is neglected in our study. Considering the limited discharge from the rivers connecting to the Bohai Sea, the river inflows are also ignored. The hydrodynamic model has been validated by our previous studies [34,48]. The result of which shows that the model used in this study is capable to simulate both the water level and velocity. To examine the effect of wind on the water exchange, the hydrodynamic model is run without and with wind forcing.

In this study, the age of water since entering the Bohai Sea is also calculated. The tracer concentration at the Bohai Strait (the open boundary of the model) is assigned as a dimensionless value of one, representing the source of the tracer. At the Bohai Strait, the age concentration there is assigned as zero to represent the zero age value there. Initially, both the tracer and the age concentrations are assigned as zero overall the modeled area. Under these conditions, the tracer and the age concentrations are calculated over time using of Equations (7) and (8), and the age is computed using Equation (4).

To support our conclusion regarding the age distribution and to examine the water transport in the Bohai Sea, we also trace the marked water in the three bays and the central basin using the tracer model. Initially, the water in Liaodong Bay, Bohai Bay, Laizhou Bay and the central basin was marked with four kinds of tracers and their concentrations are set to one in corresponding areas and zero out of the corresponding areas. The concentrations at the open boundary along the Bohai Strait 
are kept as zero. All the other parameters in the model remain the same as those of the calculation of age. The half-lives of water in the bays are calculated based on the time series of the following formula:

$$
R_{i j}(t)=\frac{M_{i i}(t)}{M_{i j 0}(t)}
$$

where $R_{i j}(t)$ is the remnant ratio of tracer $i$ in bay $j$ (both $i$ and $j$ represent the kinds of tracer marked the water in different regions), $M_{i j}(t)$ is the mass of tracer $i$ residing in bay $j$ and the $M_{i j 0}(t)$ is the total mass of tracer $i$ residing in bay $j$ at the beginning of tracer simulation.

The three models can run simultaneously, with the results of the hydrodynamic model (water level and velocity) being transferred to the age and tracer transport models immediately. The time step used in the three models is $120 \mathrm{~s}$. The period of simulation is 20 years from the beginning of 1990 to the end of 2009. To achieve a physically realistic result, a spin up period of 30 days for the hydrodynamic model was used, after which the age model and tracer transport model begin.

\section{Results and Discussion}

\subsection{Characteristics of Tides}

As mentioned above, the tide is an important factor relating to the water exchange in the Bohai Sea. Figure 2 shows the model predicted co-amplitude and co-phase maps of four major tidal components. It can be seen that there are two amphidromic systems in the Bohai Sea for semi-diurnal tidal components $\left(\mathrm{M}_{2}\right.$ and $\left.\mathrm{S}_{2}\right)$ and one amphidromic system for diurnal tidal components $\left(\mathrm{K}_{1}\right.$ and $\mathrm{O}_{1}$ ). Correspondingly, there are two amphidromic points for semi-diurnal tidal components and one amphidromic point for diurnal tidal components. The average amplitudes are approximately $0.40 \mathrm{~m}$, $0.10 \mathrm{~m}, 0.25 \mathrm{~m}$ and $0.15 \mathrm{~m}$ for $\mathrm{M}_{2}, \mathrm{~S}_{2}, \mathrm{~K}_{1}$ and $\mathrm{O}_{1}$. Consequently, the semi-diurnal tidal component, $\mathrm{M}_{2}$, is predominant in the Bohai Sea. These results generally agree with the findings of Bao et al. [49] and Jia et al. [11]. Comparison between the model predicted and field observed tidal harmonic constants (tidal amplitude and phase) in 12 stations around the Bohai Sea is shown in Figure 3. It can been seen that the model predicted tidal harmonic constants agree well with the observations, with the root mean squared errors (RMSE) of the amplitude being $0.06 \mathrm{~m}$ and the phase being $11.7^{\circ}$, indicating that the accuracy of the model used in this study is adequate for studying the water flow in the Bohai Sea.
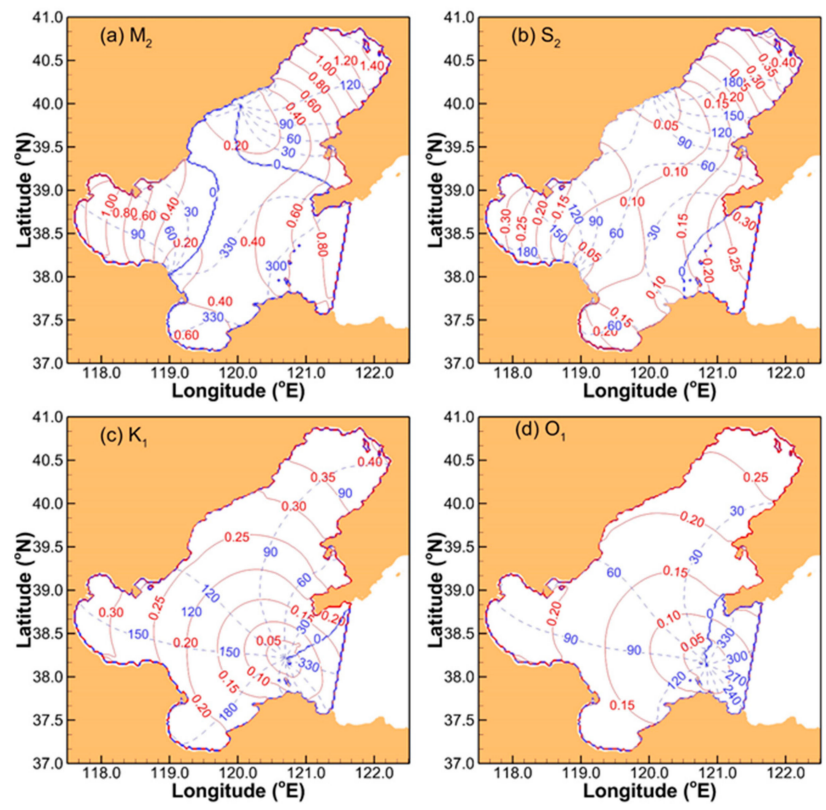

Figure 2. Predicted co-amplitude (red solid lines) and co-phase (blue dash lines) maps of major tidal components. 

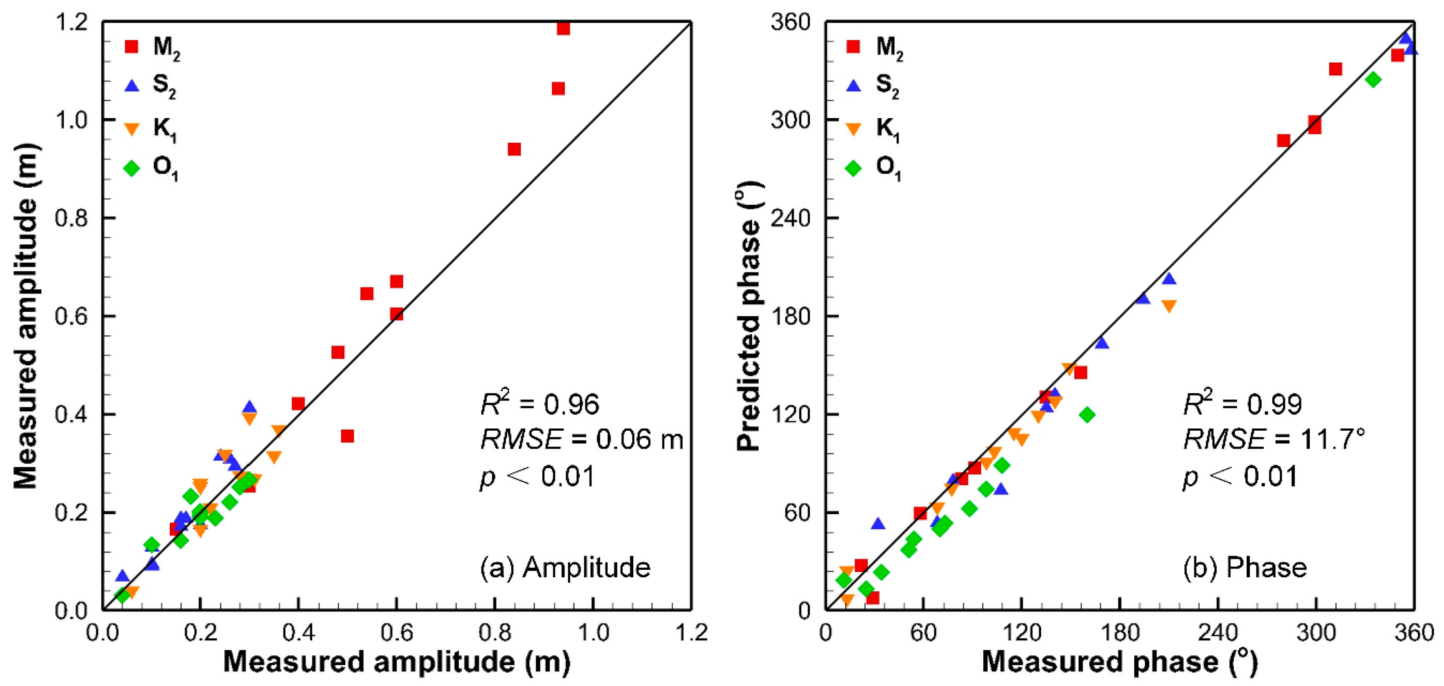

Figure 3. Comparisons between the model-predicted and observed tide amplitudes and phases. The field data are from Admiralty [44].

\subsection{Characteristics of Wind}

Figure 4 shows the frequency of the wind direction during different seasons based on the NCEP CFSR wind data during 1 January 1979 to 31 December 2010. The dominant wind direction in the winter is the northwest (NW). During spring, the wind mainly blows from the south-southwest (SSW). The wind in the summer has a wider range of direction but the dominant direction is from the south (S). The autumn is a transitional period, during which the range of the wind direction is wider, with the west (NW-SSW) wind occurring more frequently.

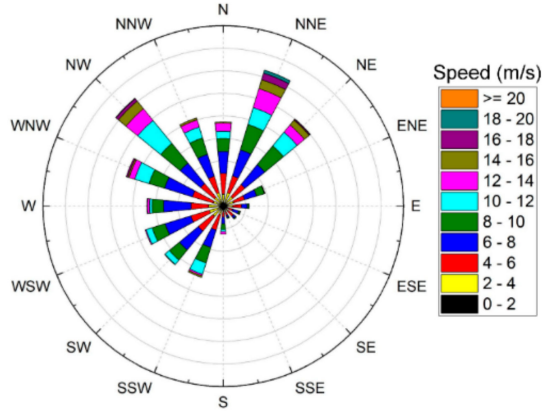

(a) Winter

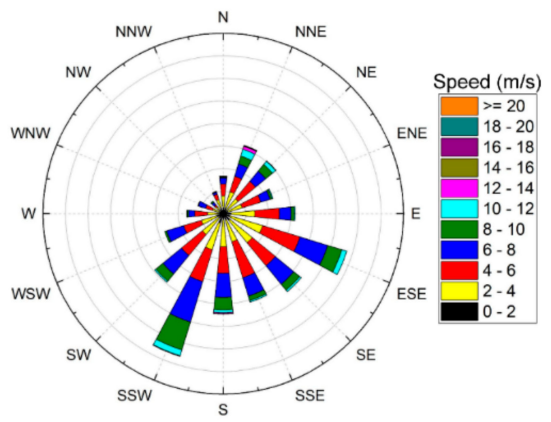

(c) Summer

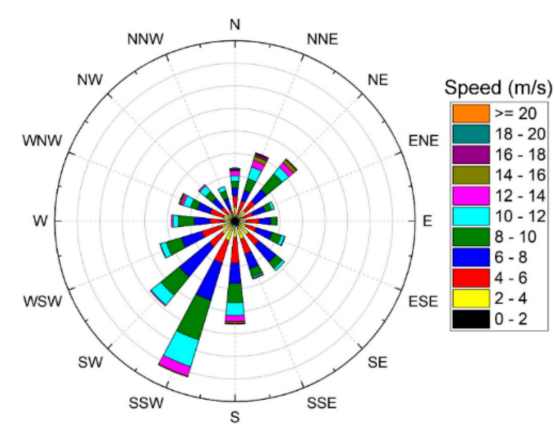

(b) Spring

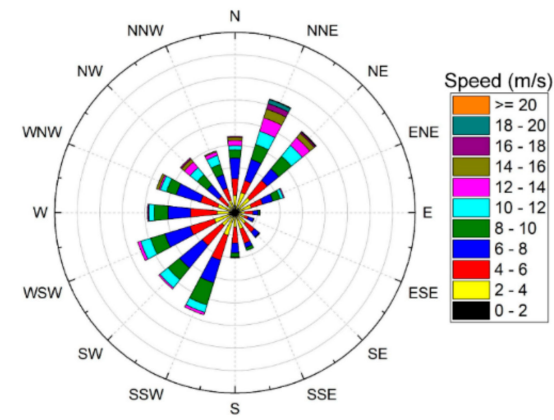

(d) Autumn

Figure 4. The wind rose (16 directions) in different seasons (based on 1979-2010).

In Figure 4, it can be found that the wind speed at each of the 16 directions also shows seasonal variation in the four seasons. The wind speed in summer is lower than in the other seasons. In the Bohai 
Sea, the higher wind speeds are often associated with northeasterly, northwesterly, and southwesterly winds and they often correspond to the dominant direction in an individual season expect in autumn. Generally, the high winds in autumn are usually present in the NNE and NE.

\subsection{Modeled Age Driven by Tidal Flow}

The calculation of age considering only the tides shows that the age distribution in the Bohai Sea achieves a relatively stable result after a 15 -year simulation. In this section, we use the monthly-averaged age distribution (Figure 5) to eliminate the fluctuations caused by the spring-neap cycles.

Analysis of the results shows that the age in the Bohai Sea ranges from 0.0-11.0 years. The maximum age is found in Laizhou Bay in which the characteristic age is about 10.0 years. Age in Liaodong Bay is the smallest among the three bays of the Bohai Sea, ranging from 1.5-6.0 years. In Bohai Bay, the characteristic age is approximately 9.0 years-between those of Liaodong Bay and Laizhou Bay. The central basin has a high age gradient. The age in the northeast ranges from 1.0 to 2.0 years, while in the southwest it is larger-ranging from 8.0 to 10.0 years. This pattern indicates that water near the Bohai Strait takes a longer time to travel through this region. Based on the concept of age, the age spatial gradient in the direction where the water transport is relatively strong should be small. According to this assumption, we can deduce the possible water transport paths (the arrows in Figure 5). Based on the age distribution and the locations of the three bays, we concluded that the water transport in the Bohai Sea is counterclockwise. It can be found that the water entering the Bohai Strait moves to Liaodong Bay, then to Bohai Bay, before reaching Laizhou Bay approximately 10 years after it enters the Bohai Strait.

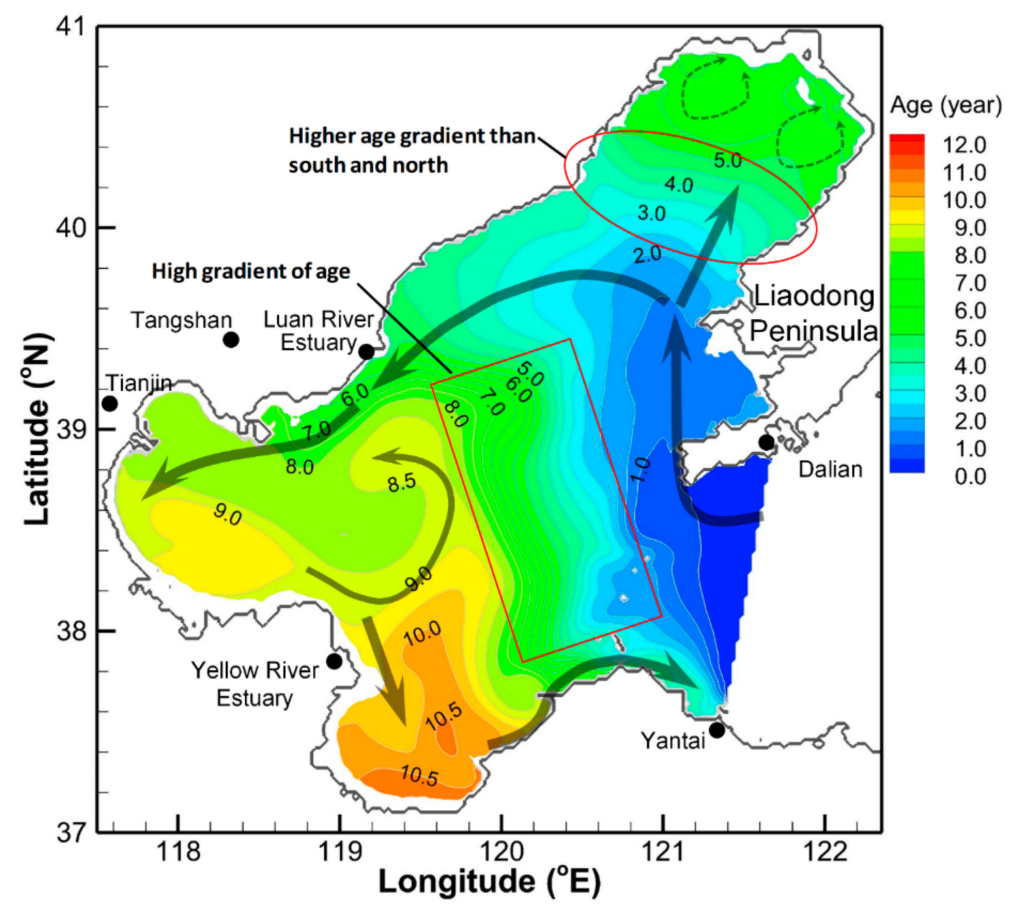

Figure 5. Monthly averaged age with water movement forced only by tidal action. The gray arrows represent the long-term water transport route deduced from the age distribution.

The age in the north part of Bohai Bay is 7-8 years and it is smaller than that in the southern part of Bohai Bay (8-9 years). Based on the phenomenon, we can find that the water in the northern part of Bohai Bay moves to the south part and the counterclockwise water transport has the influence on the most part of Bohai Bay. This conclusion is supported by Li et al. [6] and Jiang et al. [50], who found that the water in Liaodong Bay and the central basin enters Bohai Bay near the north bank of Bohai Bay and flows to the southern part of the bay along its west bank. Similarly, age near the west bank of 
Laizhou Bay is about 9-10 years and it is smaller than that near the east bank of the bay, indicating that the water in the west part of Laizhou Bay moves to its eastern part.

Regarding Liaodong Bay, the water age in the southeastern region is only 1.5-2.5 years, which is smaller than that in the southwest of the bay. However, the water age in the northern area of Liaodong Bay is higher than in the southern region, with an area of a high gradient of age in the central part of that bay. This phenomenon is distinguished from the situations in Bohai Bay and Laizhou Bay and indicates that the counterclockwise water transport in the Bohai Sea has little effects on the water in the north part of Liaodong Bay. Comparing the shape and area of Liaodong Bay to those of Bohai Bay and Laizhou Bay, we find that Liaodong Bay is long and larger. Due to this circumstance, the northern part of Liaodong Bay experiences weak water exchange with areas further south. The high age gradient in the central Liaodong Bay suggests that the water entering from the south travels slowly through this region and does not mix well with the northern portions of the bay. This finding is supported by Wei et al. [51] who considered that there are several smaller-scale tidal-induced Eulerian circulations in the north part of Liaodong Bay and the circulations make the water exchange between this region and southern Liaodong Bay difficult.

\subsection{Modeled Age Driven by Wind and Tidal Action}

When we include the effects of wind on the water motion, the age distribution in the Bohai Sea varies depending on the seasons. Figure 6 shows the simulated seasonal-averaged age in the Bohai Sea with forcing from both the wind and tidal action. It can be seen that the age of the water in the Bohai Sea ranges from 0 to 4.6 years with the influence of the tides and wind considered. Compared to the age simulated with only the tides, the maximum age is reduced by more than half. The result shows that the wind substantially accelerates the process of the water entering the Bohai Sea and it is an important contributor to the water exchange with the Yellow Sea.

When wind is included in the simulation, the maximum age within an individual bay often occurs at the far end, and the ages are nearly equal in each of the three bays. This indicates that the time for the water entering from the Bohai Strait getting to the far ends of the three bays are similar. However, the ages at the mouths of the three bays present notable differences. During winter and spring, the age near the mouth of Liaodong Bay and the northern region of the central basin ranges from 0.4 to 4.2 years. During summer and autumn, the age range in this region is reduced to 1.5-3.8 years. The age on the mouth of Laizhou Bay and the southern part of the central basin is smaller compared to the northern part of the central basin, with the value being 2.2-2.5 years during winter and spring, and 0.8-2.0 years during summer and autumn. Generally, the age in the southern region of the central basin is smaller than that in the western and northern regions, suggesting that the water transport driven by wind in the central basin may be clockwise, which conforms to the conclusion by Xu et al. [21]. The phenomenon is different from the long-term transport driven by the tides (where age suggests a counterclockwise transport, Figure 5). Under the influence of wind, a notable water transport route only seems evident in the central basin and no obvious transport route occurs among the three bays.

When considering the influence of wind on water motion, the water age in the northern part of Liaodong Bay is still large. Figure 6 shows that the age gradient in the north part of Liaodong Bay is smaller and that in the south part of it is larger. These phenomena are similar to the simulation considering only tidal action, suggesting a weak water exchange between the northern and central regions of Liaodong Bay even considering the effect of wind.

Figure 7 shows the volume-averaged ages in the different regions of the Bohai Sea and their temporal variations. The result shows that the volume-averaged age in Bohai Bay is largest among the three bays, supposing that the water entering from the Bohai Strait takes longest to enter Bohai Bay. This fact may be explained by the location of Bohai Bay, which is furthest from the Bohai Strait. 

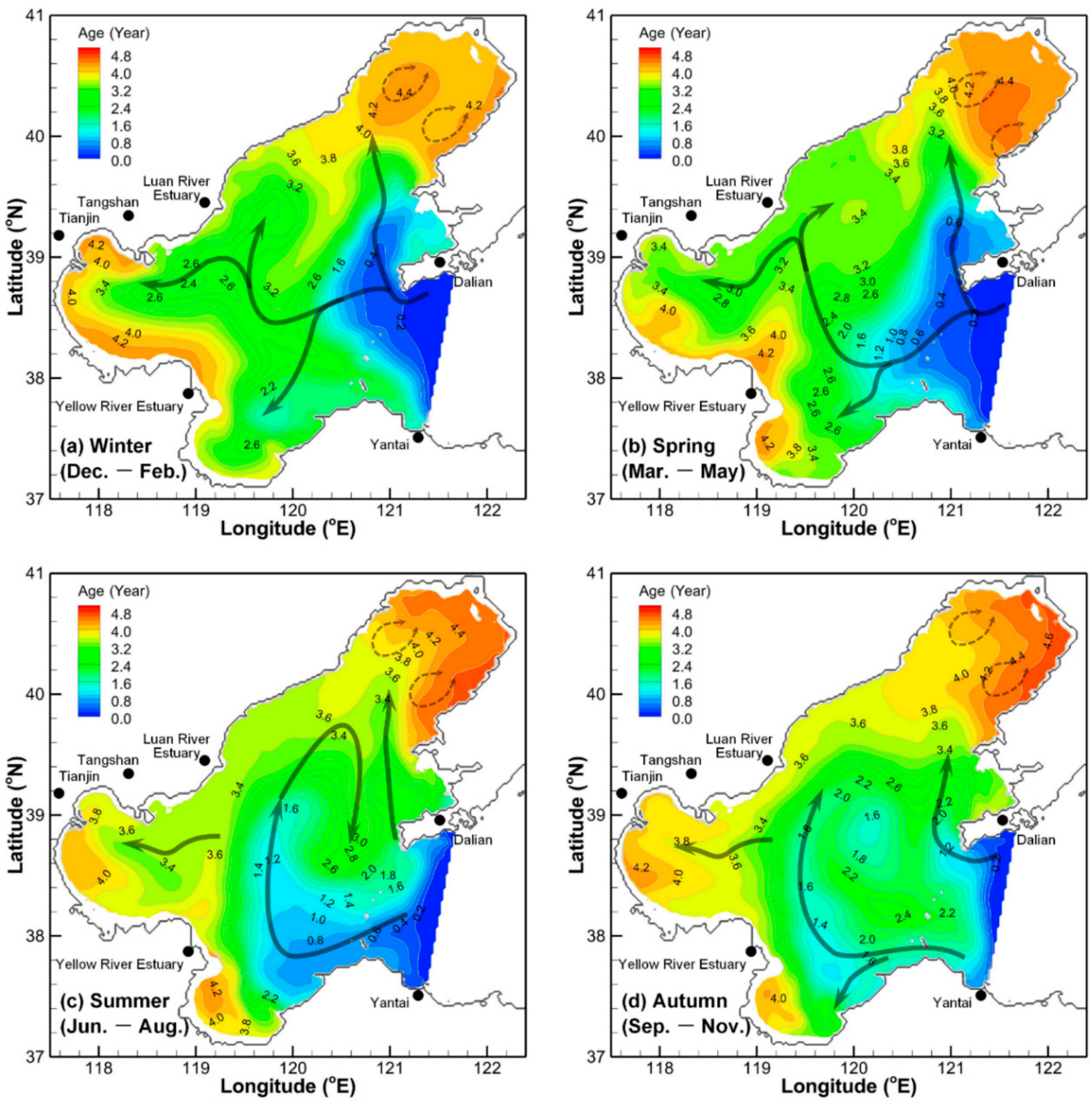

Figure 6. Seasonal-averaged age distributions in the Bohai Sea driven by the tides and wind. The solid arrows represent the long-term water transport deduced from the age distribution.

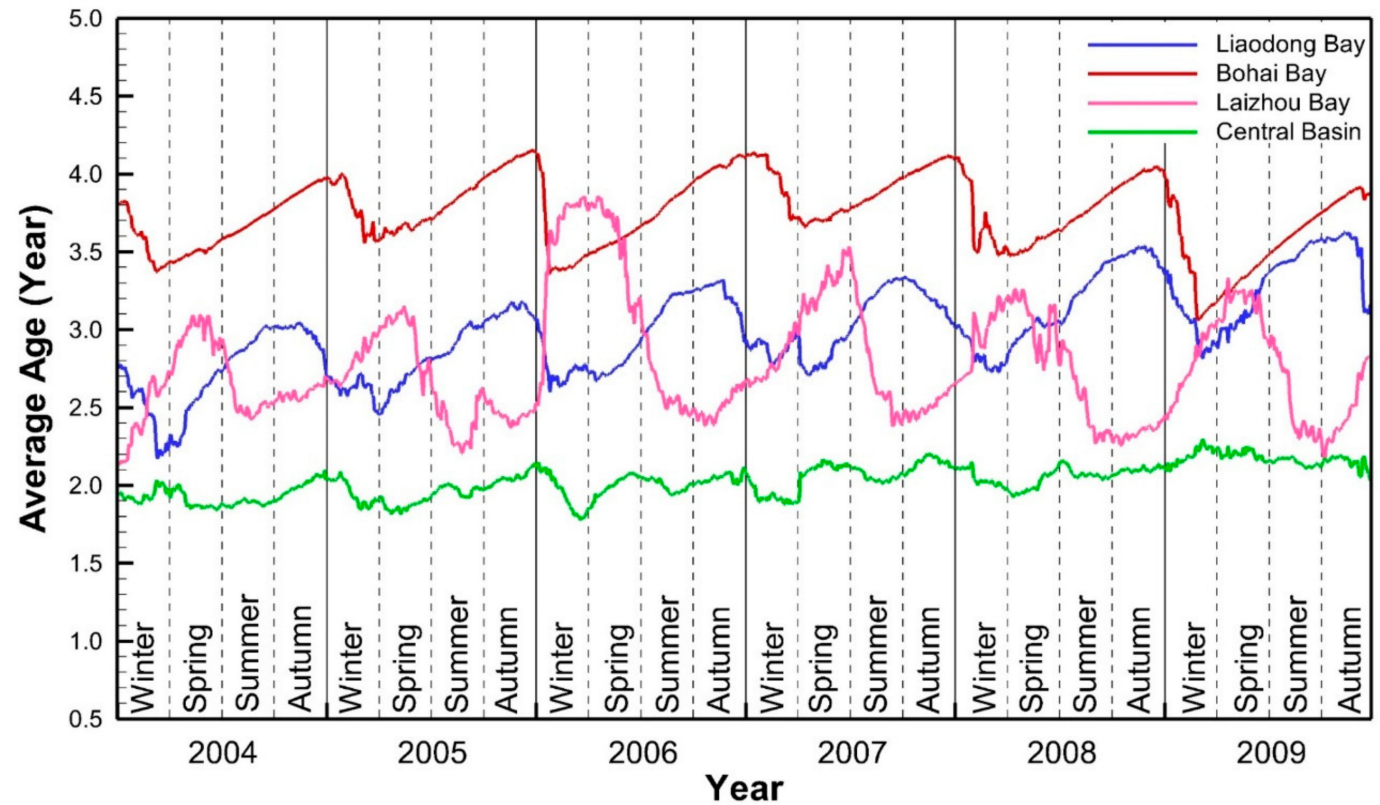

Figure 7. Volume-averaged age in the four parts of the Bohai Sea. 
The average water ages in different regions of the Bohai Sea vary seasonally. The ages in Liaodong Bay and Bohai Bay vary synchronously. Generally, the ages in the two bays decrease at the beginning of winter and increase after the end of winter with the maximums achieved at the end of autumn. In winter, the dominant wind direction is from the northwest (Figure 4a). Under this condition, the shallow water in Bohai Bay and Liaodong Bay flows to the central basin under influence of the northwest wind and the water with small age in the central basin enters the two bays. The age variation in Laizhou Bay presents the opposite trend. The water age begins to increase at the end of summer and peaks during the next winter or early spring. It then decreases during spring and summer when the southerly wind is dominant (Figure $4 \mathrm{~b}, \mathrm{c}$ ). Similar to the situation in Liaodong Bay and Bohai Bay under the influence of a prevailing northeast wind, the south wind drives the water in Laizhou Bay towards the central basin and the water with smaller age in the central basin flows into Laizhou Bay to take the place of the outflow. The average age variation in the central basin also changes with the seasons, but the amplitudes of the fluctuations are smaller than those in the three bays. Generally, the average age in the central basin varies synchronously with those in Liaodong Bay and Bohai Bay, related to the large volume of water in these bays relative to Laizhou Bay.

\subsection{Tracer Movement with Tidal Forcing}

The water initially located in Liaodong Bay, Bohai Bay, Laizhou Bay and the central Basin are marked by tracers A, B, C and D, respectively. Figure 8 shows the initial conditions of the marked tracers (Figure 8a) and the tracer concentrations after one year of the simulation driven solely by tidal action (Figure 8b-d).

Regarding Tracer A in Liaodong Bay (see Figure 8b), the concentration at the mouth of Liaodong Bay decreases to 0.2 after one year. Tracer A stretches to the central basin from the center of the mouth of Liaodong Bay and to Bohai Bay near the Luan River estuary. Near the east bank of Liaodong Bay, the concentration of Tracer A is lower. These phenomena correspond to the previous tidal-action only results (Figure 5) which showed that water from the Bohai Strait enters Liaodong Bay to the west of the Liaodong Peninsula and that the water in the western region of Liaodong Bay moves to Bohai Bay along the west bank of Liaodong Bay. In the northern part of Liaodong Bay, the tracer concentration remains high after one year, at about 0.9 . This corresponds closely with the high water age in the northern part of Liaodong Bay and large age gradient in the bay's central region (see Figure 5), representing the weak water exchange in the north part of Liaodong Bay.

After one year, the concentration of Tracer B in Bohai Bay has been reduced to lower than 0.6 (Figure 8c). It can be seen that the tracer concentration in the northern region of Bohai Bay is lower, with the minimum presenting at the northern area of the mouth of this bay. However, the concentration in the southern Bohai Bay is higher at approximately 0.5. Those phenomena result from the northern region of Bohai Bay receiving water directly from Liaodong Bay and the central basin. The water then travels to the south along a counterclockwise circulation in Bohai Bay [6,50]. A tongue of higher concentration of Tracer B extends from the southern part of the mouth of the bay to the southeast. The tracer moving out of Bohai Bay then forms two bands of higher concentration-one branch enters the western Laizhou Bay near the Yellow River estuary while the other extends to the north in the western central basin. 

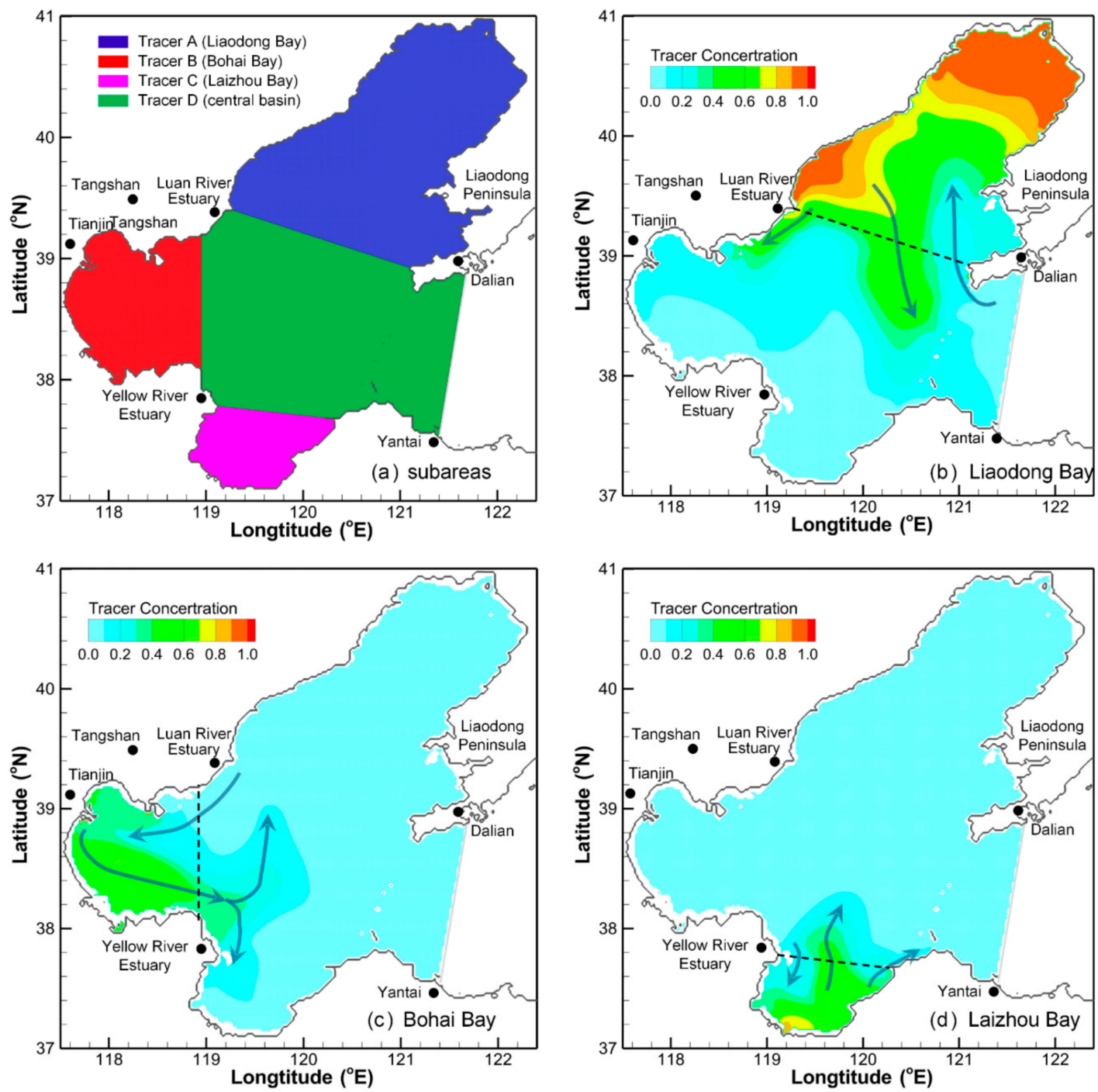

Figure 8. Tracer distribution. (a) Initial condition of the marked tracers (the colors represent the kind of the tracer). The concentrations of the tracer after one year of simulation (the end of 2009) in (b) Liaodong Bay (Tracer A), (c) Bohai Bay (Tracer B), and (d) Laizhou Bay (Tracer C).

In most of Laizhou Bay (Figure 8d), the concentration of Tracer C decreases to lower than 0.5 after a one-year simulation and the maximum of concentration is only 0.8 over a small area. Generally, the concentration in the south of it is higher compared to that near the mouth of the bay. The higher concentration of tracer (0.8) in the south of Laizhou Bay represents the weak water exchange there when forced by tidal action. At the mouth of the bay, the concentration near the eastern and central region is relatively higher compared to the west coast of the river. The concentration in the western Laizhou Bay is only 0.2, the lowest in Laizhou Bay, as a result of the water exchange with Bohai Bay.

Based on the analysis, we can find that the simulated tracer movements driven by the tidal action confirm the water exchange deduced according to the age distribution in the tide only simulation. This suggests that the findings of the water exchange based on the age distribution are reliable.

\subsection{Water Exchange among the Bays}

To study the details of the mass transport processes in the Bohai Sea, we calculated the mass ratios of individual kind of tracers residing in different regions of the Bohai Sea. Figure 9 shows the variations of remnant ratios in individual region with and without consideration of wind (the tides are considered in both the situations). 

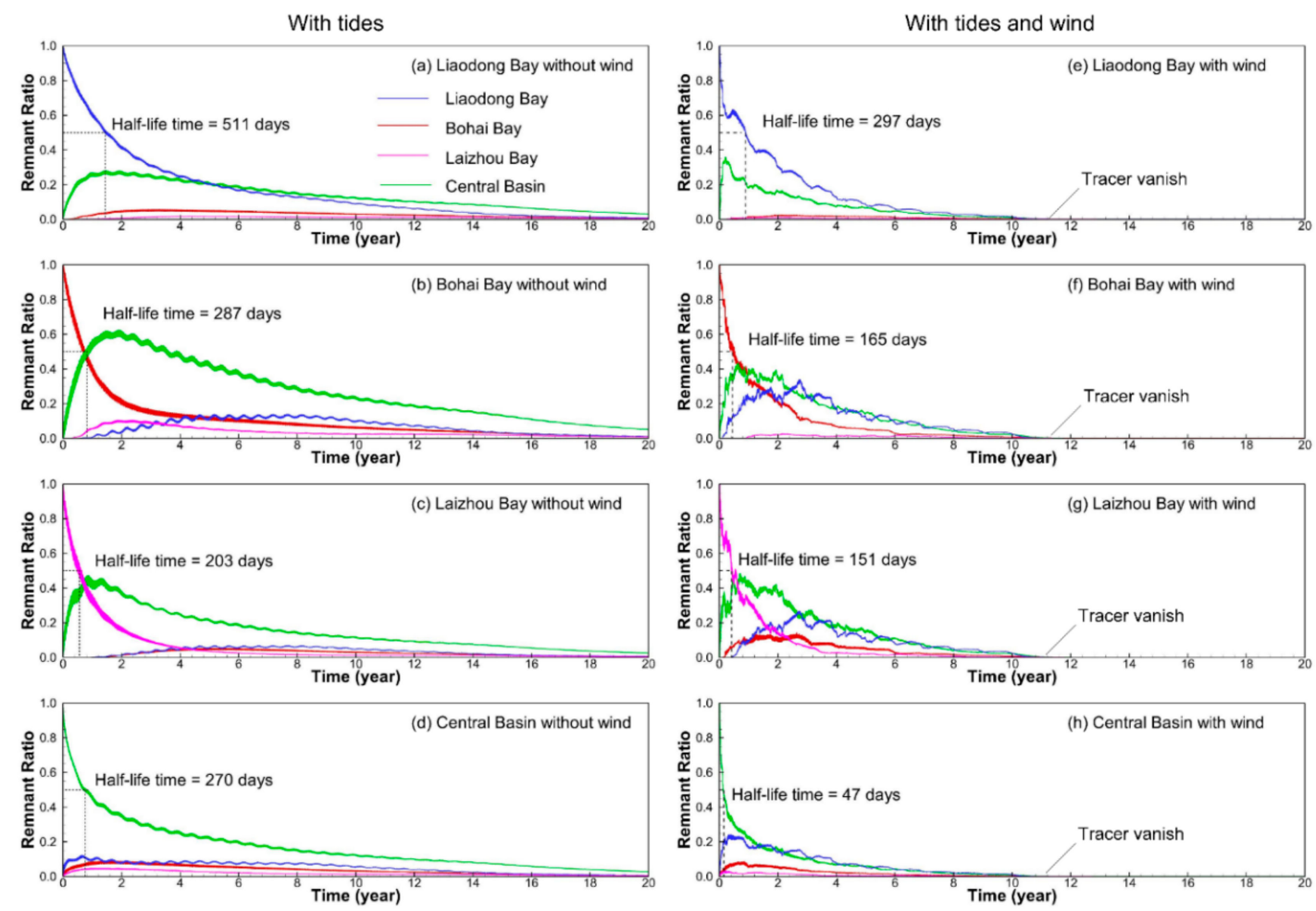

Figure 9. Remnant ratios of tracers initially residing in the four regions. The first day is 1 January 2010. (a)-(d) represent the situations only considering the tides and (e)-(h) represent the situations with both the tides and wind.

For the simulation driven only by the tides, as the remnant ratio of Tracer A in Liaodong Bay decreases (Figure 9a), the Tracer A concentration in the central basin increases quickly. The ratio of Tracer A in Bohai Bay increases as well (approximately five months after the start of the simulation) with the value being smaller than that in the central basin. The increase of the ratio for Tracer A in Laizhou Bay occurs last - more than one year after the start of the simulation. Such variations in the remnant ratios indicate that the tracer (water) flowing out of Liaodong Bay enters the central basin immediately, then enters Bohai Bay, and finally Laizhou Bay.

In Figure 9b, we see that, as the ratio of Tracer B in Bohai Bay decreases, its concentration in the central basin and Laizhou Bay increases first, and then the ratio in Liaodong Bay increases. This suggests that there is still some tracer initially located in Bohai Bay entering Liaodong Bay driven by tides and diffusion, but this requires a longer time ( 250 days). However, it also takes a much longer time ( 400 days) for Tracer C initially located in Laizhou Bay to enter Liaodong Bay (Figure 9c). In fact, based on the age distribution only considering the tides (Figure 5), we have found that there is a local current from the Yellow River estuary to the mouth of the Luan River estuary and Liaodong Bay. The remnant ratios found in Figure $9 \mathrm{~b}$ and $\mathrm{c}$ support the existence of the current. This suggests that the tracers initially located in Bohai Bay (Tracer B) and Laizhou Bay (Tracer C) travel to Liaodong Bay along with the local current.

Compared with the simulation driven only by tidal action, the remnant ratios of the four kinds of tracers under the influence of the tides and wind decrease faster. The remnant ratios of the tracers in the Bohai Sea become zero after about eleven years with the influence of the tides and wind. The half-lives (the time after which half of the mass of tracer initially located in a region is no longer found in the region) of the individual regions without and with wind are marked in Figure 9, respectively. With the influence of wind, the half-lives in the four parts of the Bohai Sea decrease by roughly $25 \%$ compared to simulations without wind, indicating that wind is a significant contributor of the water exchange in the Bohai Sea. 
In Figure 9e, we find that Tracer A moves out of Bohai Bay more quickly and its mass in the central basin increases faster than in the simulation with only tides. Driven by wind, the mass of Tracer A entering Bohai Bay and Laizhou Bay decreases. Similarly, we also find that Tracer B moves out of Bohai Bay faster. All the facts suggest that the wind accelerates the water exchange in the bays. Due to the wind, the tracers are difficult to be accumulated in the Bohai Sea.

However, the maximum of remnant ratio of Tracer B in Liaodong Bay increases and that in Laizhou Bay decreases compared to the simulations with only the tides (Figure 9b). This means that more water in Bohai Bay moves to Liaodong Bay and less water moves to Laizhou Bay when wind is considered. This results from a wind-driven clockwise transport in the central basin, which was also found based on the age distributions in simulation considering both the wind and tides. The similar situation also occurs for Tracer $\mathrm{C}$. The maximum remnant ratio of Tracer $\mathrm{C}$ in Bohai Bay and Liaodong Bay increases comparing to the situation with only the tides (Figure 9c,g). Considering the location of the three bays, those phenomena indicate that the wind contributes to the water in Laizhou Bay moving to Liaodong Bay and Bohai Bay.

\section{Conclusions}

In this study, numerical models were built to investigate the water exchange in the Bohai Sea under the effects of both tides and seasonally varying wind. The age of water entering the Bohai Sea through the Bohai Strait was calculated based on the Eulerian age theory, and the half-lives of water for each bay were calculated using simulated tracers. Based on the results, the effects of tides and wind on the water exchange in the Bohai Sea was quantified and their contributions analyzed.

When considering tidal action alone, water age increases generally counterclockwise around the sea, which indicates the tide-induced water transport in the same direction. The water ages are 2-6 years in Liaodong Bay, 9-10 years in Bohai Bay, and approximately 11 years in Laizhou Bay, respectively.

Wind alters the water exchange process significantly in the Bohai Sea, both in value and in pattern. Due to the effect of wind, the maximum age is reduced to $\sim 4.5$ years. The half-lives of the water exchange in the individual bays decrease by $47 \%$ on average compared to the simulation driven only by tides. These facts indicate that the times for water from the Bohai Strait to enter the three bays of the Bohai Sea are reduced significantly. Both analyses on the age distributions and the remnant ratios of the tracers with tides and wind suggest that the counterclockwise transport almost disappears due to the intensified water exchange among the different parts of the Bohai Sea. These metrics also indicate a clockwise water transport in the central basin of the Bohai Sea when the effects of both tides and wind are considered.

With the variation of wind, the age in each bay fluctuates, indicating the seasonal changes of physical self-purification ability in the bays. Generally, the age variations in Liaodong Bay and Bohai Bay are synchronous, and the average ages in them are small in winter and large in summer or autumn. The age variation in Laizhou Bay is anti-phase to that in Liaodong Bay and Bohai Bay, and the age reaches minimum at the end of summer. The result shows that the water exchanges in Liaodong Bay and Bohai Bay are better in winter and Laizhou Bay experiences the better water exchange during summer.

Author Contributions: Conceptualization, Y.L.; Data curation, L.T.; Formal analysis, J.S. and Z.N.; Funding acquisition, Z.N., H.L., and R.C.; Methodology, J.S.; Project administration, J.S. and L.T.; Software, J.S., Y.L., and D.Y.; Supervision, Y.L.; Writing—original draft, J.S. and Y.L.; Writing—review and editing, L.T., Y.L., Z.N., H.L., R.C., and D.Y.

Funding: This research was funded by the National Key R\&D Program of China of the grant number 2016YFA0600901 and 2016YFE0133700, and the National Natural Science Foundation of China of the grant number 51679125.

Acknowledgments: The authors acknowledge the contributions from two anonymous reviewers whose comments and suggestions are very valuable and helped us improve this work.

Conflicts of Interest: The authors declare no conflict of interest. 


\section{References}

1. Li, Z.; Wang, H.; Guo, X.; Liu, Z.; Gao, H.; Zhang, G. Influence of a Water Regulation Event on the Age of Yellow River Water in the Bohai. J. Ocean Univ. China 2017, 16, 727-737. [CrossRef]

2. Chen, C.; Chen, L.; Li, F.; Huang, Q.; Wu, L.; Zhang, W. Urgent Caution to Trace Organometal Pollution: Occurrence, Distribution and Sources of Methyltins, Butyltins and Phenyltins in Sediments from South Hangzhou Bay, China. Environ. Pollut. 2019, 246, 571-577. [CrossRef] [PubMed]

3. Rabalais, N.N.; Turner, R.E.; Wiseman, W.J. Gulf of Mexico Hypoxia, Aka the Dead Zone. Annu. Rev. Ecol. Syst. 2002, 33, 235-263. [CrossRef]

4. Howarth, R.W.; Sharpley, A.; Walker, D. Sources of Nutrient Pollution to Coastal Waters in the United States: Implications for Achieving Coastal Water Quality Goals. Estuaries 2002, 25, 656-676. [CrossRef]

5. Balcom, P.H.; Hammerschmidt, C.R.; Fitzgerald, W.F.; Lamborg, C.H.; O'Connor, J.S. Seasonal Distributions and Cycling of Mercury and Methylmercury in the Waters of New York/New Jersey Harbor Estuary. Mar. Chem. 2008, 109, 1-17. [CrossRef]

6. Li, Y.; Feng, H.; Yuan, D.; Guo, L.; Mu, D. Mechanism Study of Transport and Distributions of Trace Metals in the Bohai Bay, China. China Ocean Eng. 2019, 33, 73-85. [CrossRef]

7. Sun, J.; Tao, J. Relation Matrix of Water Exchange for Sea Bays and Its Application. China Ocean Eng. 2006, 20, 529-544.

8. Armenio, E.; Ben Meftah, M.; De Padova, D.; De Serio, F.; Mossa, M. Monitoring Systems and Numerical Models to Study Coastal Sites. Sensors 2019, 19, 1552. [CrossRef] [PubMed]

9. De Serio, F.; Mossa, M. Meteo and Hydrodynamic Measurements to Detect Physical Processes in Confined Shallow Seas. Sensors 2018, 18, 280. [CrossRef]

10. Armenio, E.; De Serio, F.; Mossa, M. Analysis of Data Characterizing Tide and Current Fluxes in Coastal Basins. Hydrol. Earth Syst. Sci. 2017, 21, 3441-3454. [CrossRef]

11. Jia, H.; Shen, Y.; Su, M.; Yu, C. Numerical Simulation of Hydrodynamic and Water Quality Effects of Shoreline Changes in Bohai Bay. Front. Earth Sci. 2018, 12, 625-639. [CrossRef]

12. Cloquet, C.; Estrade, N.; Carignan, J. Ten Years of Elemental Atmospheric Metal Fallout and Pb Isotopic Composition Monitoring Using Lichens in Northeastern France. Comptes Rendus Geosci. 2015, 347, 257-266. [CrossRef]

13. Duan, X.; Li, Y. Distributions and Sources of Heavy Metals in Sediments of the Bohai Sea, China: A Review. Environ. Sci. Pollut. Res. Int. 2017, 24, 24753-24764. [CrossRef] [PubMed]

14. Feng, S.; Zhang, J.; Wei, H. Introduction to Environmental Dynamics in the Bohai Sea; China Science Publishing \& Media Ltd.: Beijing, China, 2007; Volume 1. (In Chinese)

15. Zhang, S.; Xi, P.; Feng, S. Numerical Modelling of Stteady Circulation in the Bohai Sea. J. Shandong Coll. Oceanol. 1984, 14, 12-19. (In Chinese)

16. Bian, C.; Jiang, W.; Pohlmann, T.; Sündermann, J. Hydrography-Physical Description of the Bohai Sea. J. Coast. Res. 2016, 74, 1-12. [CrossRef]

17. Kwan, P. Some Problems Concerning the Study of the Current Structure of the near-Shore Area of China Sea. Oceanol. Limnol. Sin. 1962, 4, 121-141.

18. Zhao, B.; Fang, G.; Cao, D. Characteristics of Tidal Residual Currents and Their Relations with Coastal Current Transports in the Bohai Sea, Yellow Sea and East China Sea. Stud. Mar. Sin. 1995, 36, 1-11. (In Chinese)

19. Xu, R.; Zhao, B.; Huang, J.; Yang, Y.; Lei, F. The Mean Residual Circulations in the Bohai Sea. Mar. Sci. 2006, 30, 47-52. (In Chinese)

20. Hainbucher, D.; Wei, H.; Pohlmann, T.; Sündermann, J.; Feng, S. Variability of the Bohai Sea Circulation Based on Model Calculations. J. Mar. Syst. 2004, 44, 153-174. [CrossRef]

21. Xu, S.; Yang, J.; Wu, S.; Dong, M.; Miao, Q. Characteristics of Surface Tidal and Residual Currents of the Central Bohai Sea. Mar. Sci. Bull. 2017, 36, 128-134. (In Chinese)

22. Wei, H.; Tian, T.; Zhou, F.; Zhao, L. Numerical Study on the Water Exchange of the Bohai Sea: Simulation of the Half -Life Time by Dispersion Model. J. Ocean Univ. Qingdao 2002, 32, 519-525.

23. Xing, F.W.; Sun, J.; Li, Y.; Yuan, D.; Tao, J. Numerical Simulation of Water Exchange in Bohai Sea with Age and Half-Life Time. In Proceedings of the 35th International Association for Hydro-Environment Engineering and Research World Congress, Chengdu, China, 8-13 September 2013; Volume III and IV, p. 7. 
24. Delhez, E.J.M.; Campin, J.M.; Hirst, A.C.; Deleersnijder, E. Toward a General Theory of the Age in Ocean Modelling. Ocean Model. 1999, 1, 17-27. [CrossRef]

25. Deleersnijder, E.; Campin, J.M.; Delhez, E.J.M. The Concept of Age in Marine Modelling: I. Theory and Preliminary Model Results. J. Mar. Syst. 2001, 28, 229-267. [CrossRef]

26. Delhez, É.J.M.; Deleersnijder, É. The Concept of Age in Marine Modelling: II. Concentration Distribution Function in the English Channel and the North Sea. J. Mar. Syst. 2002, 31, 279-297. [CrossRef]

27. Meier, H.E.M. Modeling the Pathways and Ages of Inflowing Salt- and Freshwater in the Baltic Sea. Estuar. Coast. Shelf Sci. 2007, 74, 610-627. [CrossRef]

28. Zhang, W.G.; Wilkin, J.L.; Schofield, O.M.E. Simulation of Water Age and Residence Time in New York Bight. J. Phys. Oceanogr. 2010, 40, 965-982. [CrossRef]

29. Ren, Y.; Lin, B.; Sun, J.; Pan, S. Predicting Water Age Distribution in the Pearl River Estuary Using a Three-Dimensional Model. J. Mar. Syst. 2014, 139, 276-287. [CrossRef]

30. Shen, J.; Haas, L. Calculating Age and Residence Time in the Tidal York River Using Three-Dimensional Model Experiments. Estuar. Coast. Shelf Sci. 2004, 61, 449-461. [CrossRef]

31. Sun, J.; Lin, B.; Li, K.; Jiang, G. Modelling Study of Residence Time and Exposure Time in the Pearl River Estuary, China. J. Hydro Environ. Res. 2014, 8, 281-291. [CrossRef]

32. Ministry of Water Resource of the People's Republic of China. Annual Hydrological Report People's Republic of China; Ministry of Water Resource of the People's Republic of China: Beijing, China, 1990-2015. (In Chinese)

33. Li, Y.; Yuan, D.; Lin, B.; Teo, F.Y. A Fully Coupled Depth-Integrated Model for Surface Water and Groundwater Flows. J. Hydrol. 2016, 542, 172-184. [CrossRef]

34. Sun, J. Relation Matrix and Its Appliction in the Study on the Water Exchange in the Coast. Ph.D. Thesis, Tianjin University, Tianjin, China, May 2007. (In Chinese).

35. Falconer, R.; Chen, Y. Improved Representation of Flooding and Drying and Wind Stress Effects in a Two-Dimensional Tidal Numerical Model. Proc. Inst. Civ. Eng. Part 2 1991, 91, 659-678.

36. Kashefipour, S.M.; Falconer, R.A. Longitudinal Dispersion Coefficients in Natural Channels. Water Res. 2002, 36, 1596-1608. [CrossRef]

37. Nie, H.; Tao, J. Inversion of Dispersion Coefficient in Water Quality Model Using Optimal Perturbation Algorithm. Appl. Math. Mech. 2009, 30, 703-712. [CrossRef]

38. Seo, I.W.; Cheong, T.S. Predicting Longitudinal Dispersion Coefficient in Natural Streams. J. Hydraul. Eng. 1998, 124, 25-32. [CrossRef]

39. Li, X.; Yuan, D.; Tao, J. Study on Application of Random Walk Method to Calculate Water Exchange in Large-Scale Bay. Appl. Math. Mech. 2011, 32, 621-634. [CrossRef]

40. Saha, S.; Moorthi, S.; Pan, H.; Wu, X.; Wang, J.; Nadiga, S.; Tripp, P.; Kistler, R.; Woollen, J.; Behringer, D. NCEP Climate Forecast System Reanalysis (CFSR) 6-Hourly Products, January 1979 to December 2010; Research Data Archive at the National Center for Atmospheric Research; Computational and Information Systems Laboratory.: Boulder, CO, USA, 2010.

41. Qin, Z.A. Contribution to the Calculation of Wind Stress on Sea Surface. Trans. Oceanol. Limnol. 1980, 3, 1-8.

42. Navigation Guarantee Department of Chinese Navy Headquarters. Marine Chart of China; Navigation Guarantee Department of Chinese Navy Headquarters: Beijing, China, 2010.

43. Sun, J.; Tao, J.A. New Wetting and Drying Method for Moving Boundary in Shallow Water Flow Models. China Ocean Eng. 2010, 24, 79-92.

44. Admiralty. Admiralty Tidal Table and Tidal Stream Tables; the Hydrographer of the Navy: London, UK, 1990.

45. Feng, S. The Theory of Storm Surge; Science Press: Beijing, China, 1982. (In Chinese)

46. Shi, P.; Guo, H. Storm Surges of the Temperate Zone in Tanggu and Its Forecast Research. Mar. Forecast Serv. 1984, 1, 33-42. (In Chinese)

47. Fu, C.; Dong, J.; Wu, S.; Liu, Q.X. Numerical Simulation on Typical Extratropical Storm Surge in the Bohai Sea. Mar. Forecast. 2011, 28, 1-8. (In Chinese)

48. Li, Y.; Feng, H.; Zhang, H.; Sun, J.; Yuan, D.; Guo, L.; Nie, J.; Du, J. Hydrodynamics and Water Circulation in the New York/New Jersey Harbor: A Study from the Perspective of Water Age. J. Mar. Syst. 2019, 199. [CrossRef]

49. Bao, X.; Gao, G.; Yan, J. Three Dimensional Simulation of Tide and Tidal Current Characteristics in the East China Sea. Oceanol. Acta 2001, 24, 135-149. [CrossRef] 
50. Jiang, W.; Wang, J.; Zhao, J. An Observation of Current in Bohai Gulf and Its Analysis. J. Ocean Univ. Qingdao 1997, 27, 23-32. (In Chinese)

51. Wei, H.; Zhao, L.; Feng, S. Comparison of the Eulerian and Lagrangian Tidal Residuals in the Bohai Sea. Chin. J. Oceanol. Limnol. 2001, 19, 119-127. [CrossRef] 